\title{
Postnatal Maturation of Cytochrome Oxidase and Lactate Dehydrogenase Activity and Age-Dependent Consequences of Lithium-Pilocarpine Status Epilepticus in the Rat: A Regional Histoenzymology Study
}

\author{
EMMANUEL RAFFO, ESTELLE KONING, AND ASTRID NEHLIG \\ INSERM U405, Université Louis Pasteur, 67085 Strasbourg Cedex, France
}

ABSTRACT

\begin{abstract}
The lithium-pilocarpine (Li-Pilo) model of epilepsy reproduces some pathophysiological, temporal, and developmental features of human temporal lobe epilepsy. In this model, rates of cerebral glucose utilization measured by the $\left[{ }^{14} \mathrm{C}\right] 2$-deoxyglucose technique increased during the initial status epilepticus (SE) and decreased during the latent or chronic periods. To correlate these metabolic changes with the activities of the enzymes of the glycolytic and tricarboxylic acid cycle pathways, we measured by histoenzymology the regional activity of two key enzymes of glucose metabolism, lactate dehydrogenase (LDH) for the anaerobic pathway and cytochrome oxidase (CO) for the aerobic pathway coupled to oxidative phosphorylation, at various times after SE induced by Li-Pilo in 10- (P10), 21-d-old (P21) and adult rats for $\mathrm{CO}$ and in adult rats only for $\mathrm{LDH}$. $\mathrm{CO}$ activity was slightly affected in P10 and P21 rats only at 4 and $24 \mathrm{~h}$ and normalized by $14 \mathrm{~d}$ after SE. In adult rats, CO activity decreased at 4 and $24 \mathrm{~h}$ in damaged areas, like entorhinal cortex, hippocampal CA3 area, amygdala, and thalamus. At $14 \mathrm{~d}$ after SE, CO activity was decreased only in entorhinal cortex and increased in brainstem regions involved in the remote control of seizures. In
\end{abstract}

adult rats, LDH activity decreased at $24 \mathrm{~h}$ and $14 \mathrm{~d}$ after SE in sensorimotor and entorhinal cortex. These data show that the enzymatic equipment underlying the metabolism of glucose is not severely affected by Li-Pilo SE and confirm our previous observations concerning the relative metabolic hyperactivity of brain regions involved in the seizure circuit despite marked neuronal loss. (Pediatr Res 56: 647-655, 2004)
CA1, CA1 layer of the hippocampus
CO, cytochrome oxidase
DZP, diazepam
LCMRgles, local cerebral metabolic rates for glucose
LDH, lactate dehydrogenase
Li-Pilo, lithium-pilocarpine
OD, optical density
P, postnatal day
SE, status epilepticus
2DG, 2-deoxyglucose

Clinical studies suggest that the development of temporal lobe epilepsy is an age-dependent and progressive process (1-3). The nature of the underlying pathophysiological mechanisms and their differences in mature and immature brain remain poorly understood. In this respect, the model of epilepsy induced in rats by Li-Pilo is a useful tool because it reproduces most clinical, developmental, and neuropathological features of human temporal lobe epilepsy $(4,5)$.

The consequences of Li-Pilo are age dependent (4-7). In adult rats, Li-Pilo leads to SE followed by a latent seizure-free

Received October 24, 2003; accepted March 22, 2004.

Correspondence: Astrid Nehlig, Ph.D., INSERM U 405, Faculty of Medicine, 11 rue Humann, 67085 Strasbourg Cedex, France; e-mail: nehlig@neurochem.u-strasbg.fr

Supported by grants from the Institut National de la Santé et de la Recherche Médicale (INSERM U398) and from the Fondation pour la Recherche Médicale (Paris, France).

DOI: 10.1203/01.PDR.0000139604.47609.8C phase of a mean duration of 14-25 d. Thereafter, all animals enter the chronic phase of the disease and exhibit spontaneous recurrent limbic seizures with generalization. Neuronal damage is located mainly in the hippocampus, dentate gyrus, piriform and entorhinal cortices, septum, thalamus, amygdala, and neocortex $(4,5,7)$. In 21-d-old rats (P21), a more moderate pattern of neuronal damage is observed in the hippocampus, amygdala, piriform and entorhinal cortices, and some thalamic nuclei. About $70-80 \%$ of the rats display spontaneous recurrent limbic seizures after a latent phase of a mean duration of $73 \mathrm{~d}(5,7)$. In P10 rats, Li-Pilo-induced SE does not lead to neuronal damage or spontaneous recurrent seizures $(5,7)$.

In previous studies on this model, we have shown that LCMRglcs measured by the quantitative autoradiographic $\left[{ }^{14} \mathrm{C}\right] 2 \mathrm{DG}$ technique adapted to the immature rat (8) increase by $300-600 \%$ in the vast majority of structures in P10, P21, 
and adult rats undergoing Li-Pilo SE (9). This metabolic activation is marked even in P10 rats in which the density of the blood-brain barrier glucose transporter GLUT1 is low (10). Conversely, during the latent and chronic phase, LCMRgles are decreased in many regions with neuronal damage in rats exposed to Li-Pilo SE at P21 or at the adult stage. They are similar to control levels in rats exposed to SE at P10 $(5,7,11)$.

To try to gain further knowledge on the characteristics of cerebral glucose metabolism in this model of epilepsy, in the present study, we measured by histoenzymology the regional activity of the two key enzymes of glucose metabolism, LDH as the final enzyme of the anaerobic pathway and $\mathrm{CO}$ as the enzyme of the final step of oxidative phosphorylation. $\mathrm{CO}$ and LDH histoenzymology has been extensively used to map the functional activity in the normal adult brain (12-16), or during development and aging (17-21). The purpose of the present study was 2-fold; firstly, we mapped the changes in $\mathrm{CO}$ and LDH activity in the rat brain during normal maturation, between P10 and the adult stage; then, we measured the activity of $\mathrm{CO}$ in P10, P21, and adult rats and that of LDH in adult rats subjected to Li-Pilo-induced SE. Changes in the level of activity of $\mathrm{CO}$ and $\mathrm{LDH}$ in representative brain regions during the acute (4 and $24 \mathrm{~h}$ after the onset of SE) and the latent phase of the epilepsy (14 d after SE) were correlated to previously mapped LCMRglcs and neuropathological damage $(5,7,9,11)$. The reasons why we limited our measurement of LDH activity to adult animals exposed to Li-Pilo are as follows: First, because, according to our previous studies $(5,7,9,11)$, this is the only age at which there is marked damage that translates into changes in metabolic activity during the latent and chronic phases $(5,7,11)$. Therefore, this is the only age at which we could expect long-lasting changes in enzyme activity that could impact on brain function. Second, in the brain, glucose is normally fully oxidized and, although a close correlation between LCMRglcs and enzyme activity was shown for CO (16), this is not the case for LDH.

\section{METHODS}

Animals and induction of SE. For breeding purposes, adult Sprague-Dawley rats (Janvier Breeding Center, Le Genest-StIsle, France), one male and two females by cage, were housed together in mating groups for $5 \mathrm{~d}$. After delivery, litters were reduced to 10 pups for homogeneity (day of birth was considered as d 0). Adult male Sprague-Dawley rats were provided by the same breeder. The animals were maintained at $22^{\circ} \mathrm{C}$ room temperature under a $12 \mathrm{~h} / 12 \mathrm{~h}$ normal light/dark cycle (lights on at $0700 \mathrm{~h}$ ) in uncrowded animal facilities with food and water ad libitum. The experiments were performed on a total number of 88 immature and adult rats. All animal experimentation was performed in accordance with the rules of the European Communities Council Directive of November 24, 1986 (86/609/EEC), and the French Department of Agriculture (License No. 67-97). All animal experiments were approved by the Animal Research Board of University Louis Pasteur and all efforts were made to minimize animals' suffering.

SE was induced by the intraperitoneal injection of lithium chloride $(3 \mathrm{mEq} / \mathrm{kg}) \quad 18-20 \mathrm{~h}$ before the s.c. injection of pilocarpine $(60,30$, and $25 \mathrm{mg} / \mathrm{kg}$ in P10, P21, and adult rats, respectively). P21 and adult rats received $1 \mathrm{mg} / \mathrm{kg}$ methylscopolamine $30 \mathrm{~min}$ before the convulsant to reduce the peripheral consequences of pilocarpine administration. Control P21 and adult animals received also methylscopolamine and control animals of all ages received lithium chloride and an equivalent volume of saline instead of pilocarpine. By $2 \mathrm{~h}$ after the onset of SE, P21 and adult rats received an intramuscular injection of $2.5 \mathrm{mg} / \mathrm{kg}$ DZP (Valium, Roche, Basel, Switzerland) to improve survival and relieve anxiety. Adult rats received a second injection of $1.25 \mathrm{mg} / \mathrm{kg}$ DZP $10 \mathrm{~h}$ after the first one. The effects of SE on CO activity were studied in P10, P21, and adult animals and those on LDH activity were measured only in adult rats at $4 \mathrm{~h}, 24 \mathrm{~h}$, and $14 \mathrm{~d}$ after the onset of SE. An additional control group not receiving any drug was used to study the basal postnatal maturation of $\mathrm{CO}$ and $\mathrm{LDH}$ activities in P10, P21, P35, and adult rats (six rats at each age).

In the present study, the clinical signs of SE were identical to our previous reports $(7,9,11)$. Briefly, within 5 min after pilocarpine injection, P21 and adult rats developed diarrhea, piloerection, and other signs of cholinergic stimulation. During the following 15-20 min, rats exhibited head bobbing, scratching, chewing, and exploratory behavior. Recurrent seizures started around 15-20 min after pilocarpine administration and associated episodes of head and bilateral forelimb myoclonus with rearing and falling. They progressed to SE at about 30-35 min after pilocarpine. SE was considered to start after three consecutive stage $\mathrm{V}$ seizures (clonic seizures, rearing and falling). In P10 rats, clinical ictal signs were less manifest, appeared after 15-20 min, and were mainly characterized by hyperactivity, continuous scratching, and masticatory automatisms. SE was reached after a delay of about $45-50 \mathrm{~min}$ and characterized by intense body tremor on the four paws without falling or rearing and by tonic extension of the tail. During SE, clonic seizures occurred continuously for $4-5 \mathrm{~h}$ after pilocarpine in P10 rats and 8-10 h in P21 and adult rats. After the end of SE, occasional recurrent seizures occurred over the $24 \mathrm{~h}$ after the onset of SE in P21 and adult rats. SE was induced in a total number of 19 P10 rats, 22 P21 rats, and 24 adult rats. From this number 1 of 19 P10 rats (5\%), 3 of 22 P21 rats $(14 \%)$, and 6 of 24 adult rats (25\%) died during the course of $\mathrm{SE}$ or over the first $24 \mathrm{~h}$ after SE. All control animals receiving Li-saline-12 rats at $\mathrm{P} 10,12$ rats at $\mathrm{P} 21$, and 12 adult rats-survived.

Histoenzymatic measurement of $\mathrm{CO}$ and $\mathrm{LDH}$ activities. For the histochemical measurement of $\mathrm{CO}$ and LDH activities, rats were deeply anesthetized with pentobarbital and immediately killed by decapitation. This procedure was used to prevent any possible effect of the anesthesia on enzyme activity. Brains were dissected out and frozen in methylbutane chilled to $-30^{\circ} \mathrm{C}$. Coronal brain sections of $20-\mu \mathrm{m}$ thickness obtained in a cryostat at 11 preselected brain levels were mounted onto gelatin-coated glass slides. Sections were taken at the following anteroposterior levels: prefrontal cortex, caudate-putamen, globus pallidus, anterior thalamus, dorsal hippocampus, medial thalamus, ventral hippocampus, superior colliculus, inferior colliculus, cerebellar nuclei, and cerebellar cortex. For the assessment of either $\mathrm{CO}$ or LDH activity, all sections of all rat 
brains (three slides for each animal) were incubated together on the same day and in the same incubation mixture to avoid any variation in incubation conditions for the final measurement of OD readings representative of enzyme activities.

For the measurement of the $\mathrm{CO}$ (cytochrome $c$ oxidase; ferrocytochrome c: oxygen reductase, EC 1.9.3.1) activity, diaminobenzidine histochemistry was carried out according to the method of Wong-Riley (16), modified by Darriet et al. (13). The incubation was performed at $38^{\circ} \mathrm{C}$ in the dark for $2 \mathrm{~h}$ in 0.1 $\mathrm{M}$ phosphate buffer $\mathrm{pH} 7.4$, containing $0.25 \mathrm{mg} / \mathrm{mL}$ cytochrome $c$ (grade III, Sigma Chemical Co., Saint-Louis, MO) and $0.05 \%$ 3,3'-diaminobenzidine tetrachloride (Sigma Chemical Co.). In this reaction, cytochrome $c$ becomes enzymatically reduced by electron transfer from diaminobenzidine. By oxidation, diaminobenzidine polymerizes and precipitates as a brown reaction product. At the end of the incubation, sections were rinsed, dehydrated in successive baths of increasing concentration of ethanol followed by LMR (Labo Moderne, Paris, France), and coverslipped in Histolaque (Labo Moderne).

For the demonstration of LDH (EC 1.1.1.27), the method of Jacobsen (22) modified by Borowsky and Collins (12) was used. The incubation was carried out for $5 \mathrm{~min}$ at $37^{\circ} \mathrm{C}$ in 50 $\mathrm{mM}$ Tris- $\mathrm{HCl}$ buffer $\mathrm{pH}$ 7.0, containing $100 \mathrm{mM}$ DL-lactate (Sigma Chemical Co.), 4 mM NAD ${ }^{+}$(grade II, Roche Molecular Biochemicals, Mannheim, Germany), $4.9 \mathrm{mM}$ (0.4\%) nitroblue tetrazolium, $0.33 \mathrm{mM}$ phenazine methosulfate, and $10 \%(\mathrm{wt} / \mathrm{vol})$ polyvinyl alcohol. This reaction utilizes phenazine methosulfate as electron carrier. Lactate oxidation leads to the formation of $\mathrm{NADH}+\mathrm{H}^{+}$, which reduces nitroblue tetrazolium and generates blue formazan. Incubation time is shortened as much as possible and the presence of polyvinyl alcohol restricts movement of the tetrazolium reaction product. After incubation, sections were rinsed in water and fixed in $10 \%$ neutral formalin. They were then washed with distilled water and coverslipped in acquovitrex (Carlo Erba, Milan, Italy).

For evaluation of both enzyme activities, absolute OD measurements were performed on sections using an imageprocessing system (Biocom-500, Biocom, Les Ulis, France). This procedure was used because a direct correlation between $\mathrm{OD}$ and spectrophotometric measurements has been shown for both CO and LDH activities $(12,13)$. OD measurements were made bilaterally for each structure anatomically defined according to the stereotaxic atlas of Paxinos and Watson (23). All readings were corrected for background (e.g. glass, inclusion medium, and coverslip) and nonspecific diaminobenzidine (CO) and nitroblue tetrazolium (LDH) reaction by incubation of a set of sections without substrate and cofactors. They usually included the whole structure or nucleus of interest, except in heterogeneous structures like the cerebral cortex, where layers III and IV were counted and readings were performed by an observer who was blind to the age and treatment of the animals.

Statistical analysis. CO and LDH activities were determined in 20 brain regions of five to seven rats per group. OD measurements of enzyme activities at each age (maturation study) or at each time after SE (Li-Pilo study) were compared by means of the Kruskal-Wallis test for multiple comparisons followed by a Mann-Whitney $U$ test. In the maturation study, the data of one age group were compared with those of the preceding age, whereas in the study on Li-Pilo SE, the data of each group of seizing animals were compared with those of the corresponding controls.

\section{RESULTS}

Postnatal maturation of $\mathrm{CO}$ and $\mathbf{L D H}$. At all ages, highest levels of $\mathrm{CO}$ activity were present in occipital and parietal cortex, hippocampal CA3 pyramidal cell layer, ventrolateral thalamus, cerebellar cortex, and nuclei (Figs. 1 and 2 and data not shown). Lowest levels of activity were found in cingulate cortex, septal nuclei, caudate nucleus, and white matter areas; the ratio between the lowest OD reflecting $\mathrm{CO}$ activity in the corpus callosum and the highest OD reflecting CO activity in cerebellar nuclei reached a value of 5 . Different profiles of maturation could be distinguished (Figs. 1 and 2). At P10, the activity of $\mathrm{CO}$ was already maximal in posterior regions like medullary reticular formation and did not change with further maturation. In all other regions, the activity of $\mathrm{CO}$ significantly increased between P10 and P21. After that age, $\mathrm{CO}$ activity did not change in most brain regions, or significantly increased between P21 and P35, mostly in cortical areas such as the temporal cortex. Later in development, i.e. between P35 and
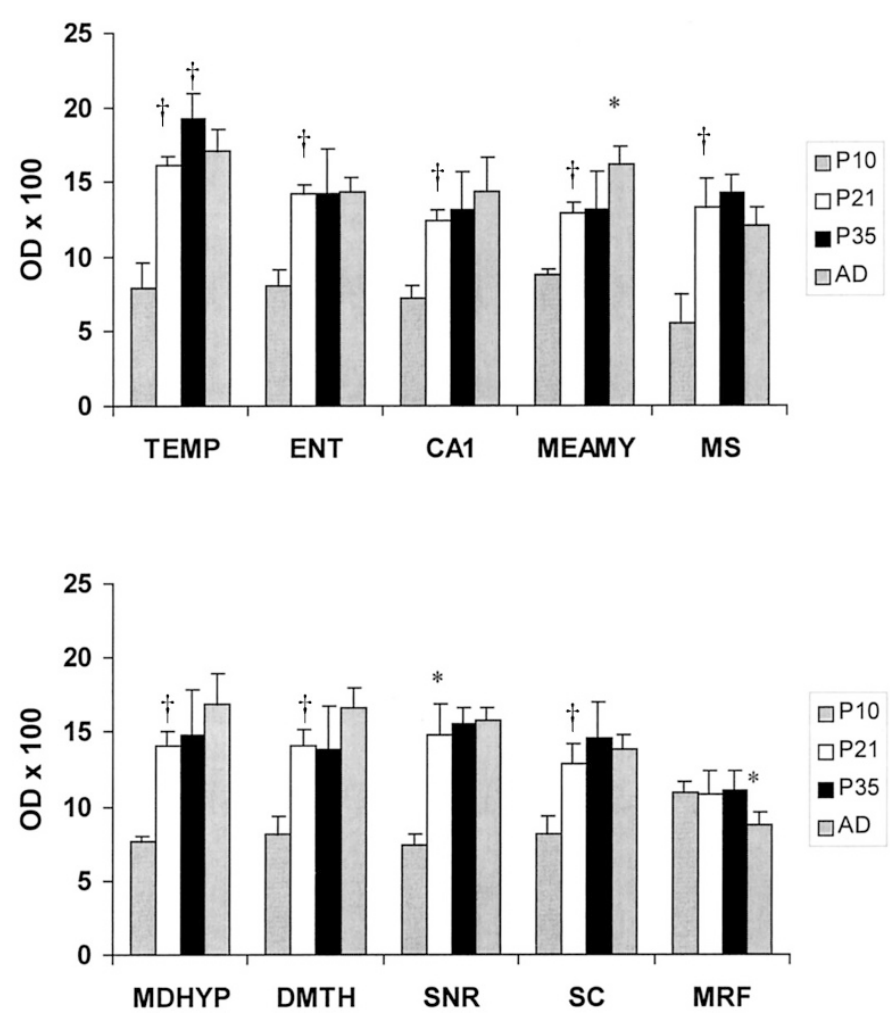

Figure 1. Postnatal maturation of $\mathrm{CO}$ activity in representative areas of the rat brain. Values are expressed as means and SD of OD $\times 100$ of six animals per group. TEMP, temporal cortex; $E N T$, entorhinal cortex; $C A 1$, CA1 layer of the hippocampus; $M E A M Y$, medial amygdala; $M S$, medial septum; $M D H Y P$, mediodorsal hypothalamus; $D M T H$, dorsomedial thalamus; $S N R$, substantia nigra pars reticulata; $S C$, superior colliculus; $M R F$, medullary reticular formation. ${ }^{*} p<$ $0.05, \dagger p<0.01$, statistically significant differences between one age and the preceding one. 


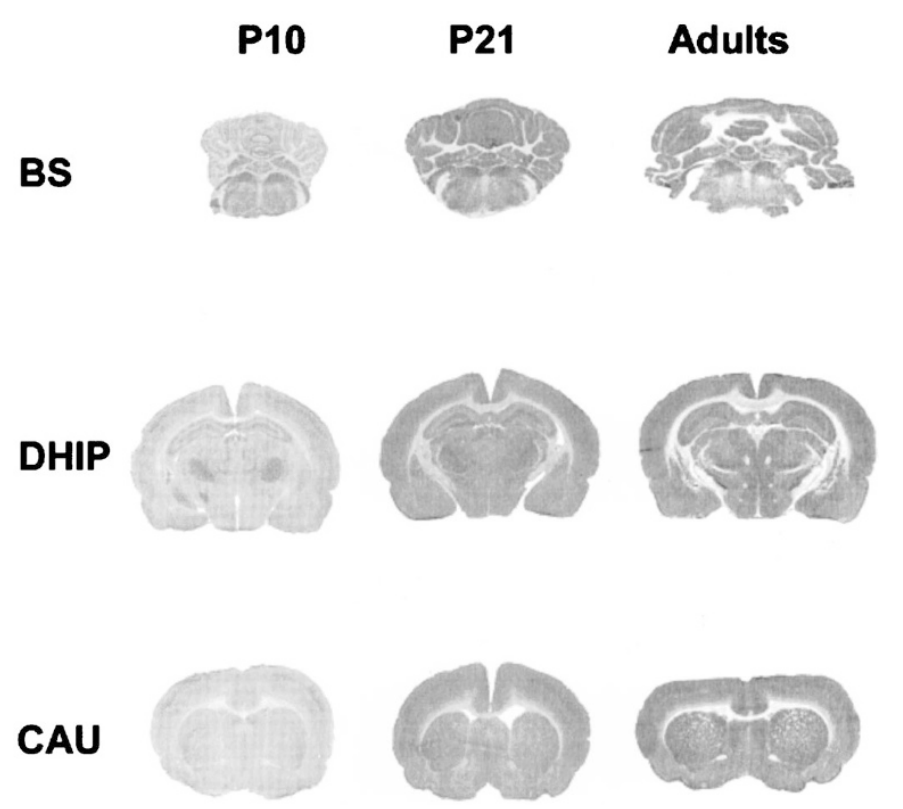

Figure 2. Rat brain sections showing the histoenzymologic reaction for $\mathrm{CO}$ activity, taken at the brainstem ( $B S$, upper row), dorsal hippocampus (DHIP, middle row), and caudate nucleus (CAU, lower row) in P10, P21, and adult rats. These images show the increase in $\mathrm{CO}$ activity mostly prominent between $\mathrm{P} 10$ and P21 and the areas of highest activity, such as the brainstem and the ventral thalamus in P10 rats and the cortex and hippocampus in P21 and adult rats.

the adult age, $\mathrm{CO}$ activity increased further only in the medial amygdala.

The distribution of LDH activity was more homogeneous than that of $\mathrm{CO}$ activity (Fig. 3). At P10, lowest levels were found in posterior regions and highest in cerebral cortex and forebrain. The ratio between the highest and lowest LDH activity at that age reached a value of 2.4. LDH activity did not change with age in the substantia nigra pars reticulata and medullary reticular formation (Fig. 3). In all other structures, the activity was maximal at P10 and significantly decreased between P10 and P21. Thereafter, there was no further change of LDH activity with maturation in any brain region.

Effects of Li-Pilo SE on CO activity in immature and adult rats. In P10 rats studied $4 \mathrm{~h}$ after SE, CO activity significantly decreased by $14-18 \%$ in medial and basolateral amygdala and ventrolateral thalamus. By $24 \mathrm{~h}$ after SE, CO activity was not different from control levels, except in medial amygdala where it remained significantly decreased. By $14 \mathrm{~d}$ after SE, CO activity was similar in animals subjected to Li-Pilo and agematched controls.

In P21 rats studied $4 \mathrm{~h}$ after SE, CO activity was similar in control and seizing animals, except for a significant $12 \%$ decrease in medial amygdala (Table 2). At $24 \mathrm{~h}$ after SE, CO activity was not different from control levels, except in hippocampal CA3 area where it was significantly decreased by $21 \%$. At $14 \mathrm{~d}$ after SE, CO activity was similar in animals subjected to Li-Pilo and age-matched controls.

In adult rats studied $4 \mathrm{~h}$ after SE, CO activity underwent a $13-16 \%$ significant decrease compared with control levels in hippocampal CA3 area, medial amygdala, all thalamic nuclei, and substantia nigra pars reticulata (Table 3 ). At $24 \mathrm{~h}$ after SE, the decrease in $\mathrm{CO}$ activity was statistically significant in
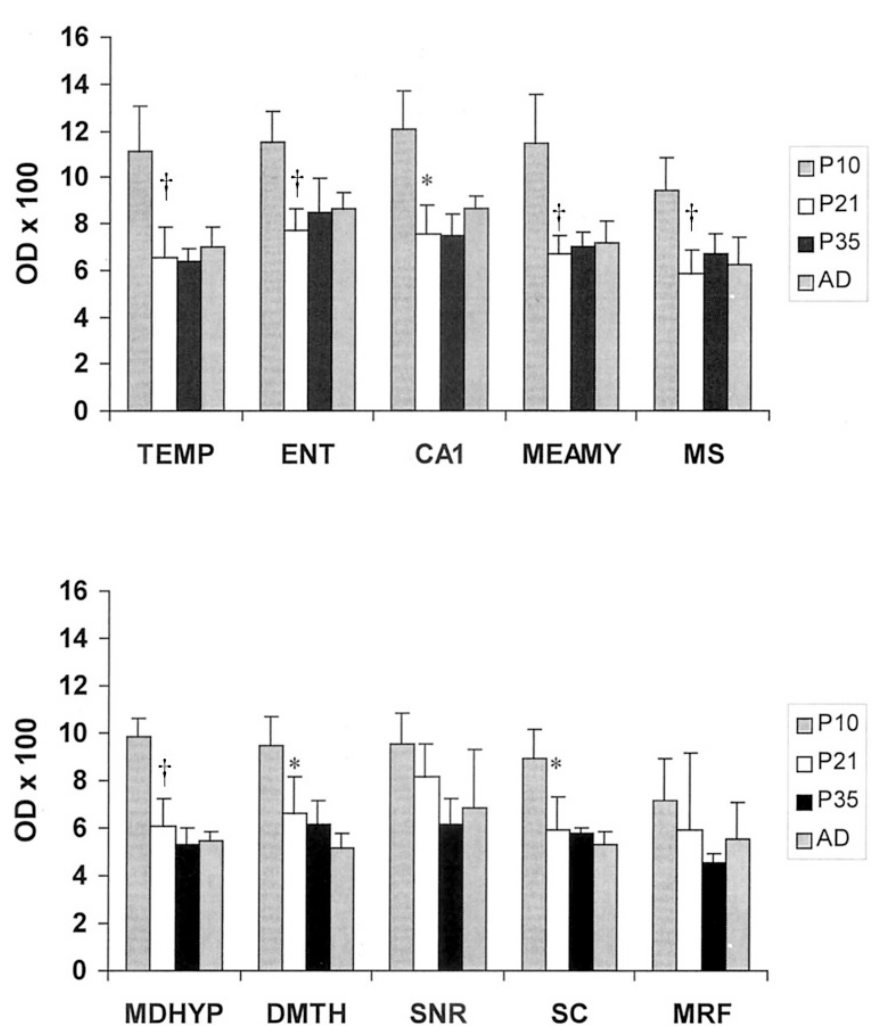

Figure 3. Postnatal maturation of LDH activity in representative areas of the rat brain. Values are expressed as means and SD of OD $\times 100$ of six animals per group. TEMP, temporal cortex; $E N T$, entorhinal cortex; $C A 1$, CA1 layer of the hippocampus; $M E A M Y$, medial amygdala; $M S$, medial septum; $M D H Y P$, mediodorsal hypothalamus; DMTH, dorsomedial thalamus; SNR, substantia nigra pars reticulata; $S C$, superior colliculus; $M R F$, medullary reticular formation. ${ }^{*} p<0.05, \dagger p<0.01$, statistically significant differences between one age and the preceding one.

entorhinal cortex, hippocampal CA3 area, medial amygdala, and substantia nigra pars reticulata. Finally, at $14 \mathrm{~d}$ after SE, $\mathrm{CO}$ activity was significantly reduced in Li-Pilo compared with saline-exposed animals in entorhinal cortex, caudate-putamen, superior and inferior colliculi, and pontine reticular formation.

Effects of Li-Pilo SE on LDH activity in adult rats. In adult rats studied at $4 \mathrm{~h}$ after SE, LDH activity reached similar levels in all areas of control and Li-Pilo-exposed animals (Table 4). At $24 \mathrm{~h}$ after SE, there was a significant $9-20 \%$ increase in LDH activity in piriform cortex, mediodorsal thalamus, and superior colliculus. At $14 \mathrm{~d}$ after SE, CO activity was similar in most brain regions of Li-Pilo- and saline-exposed animals, except for a significant 26 and $72 \%$ decrease in sensorimotor and entorhinal cortex, respectively.

\section{DISCUSSION}

Methodological considerations. Histoenzymology techniques allow visualization of regional rates of enzyme activity. They show the precise location of the products of the enzymatic reaction at the regional, cellular, and subcellular level and the relative degrees of enzyme activity can be quantified by optical densitometry $(13,16)$. However, conversely to biochemical approaches, they reveal only relative and nonabsolute levels of enzyme activity (16). These techniques have been used to map the activity in the normal 
Table 1. Effect of lithium-pilocarpine SE on cytochrome oxidase activity in various cerebral regions of $P 10$ rats

\begin{tabular}{|c|c|c|c|c|c|}
\hline & Control P10 rats & $4 \mathrm{~h}$ after SE & $24 \mathrm{~h}$ after SE & Control P24 rats & $14 \mathrm{~d}$ after SE \\
\hline \multicolumn{6}{|l|}{ Cerebral cortex } \\
\hline Frontal & $6.48 \pm 2.11$ & $8.14 \pm 0.87$ & $7.67 \pm 1.78$ & $15.92 \pm 1.83$ & $15.11 \pm 2.91$ \\
\hline Piriform & $7.71 \pm 2.39$ & $11.19 \pm 1.79$ & $9.07 \pm 3.11$ & $16.13 \pm 3.34$ & $15.28 \pm 4.12$ \\
\hline Sensorimotor & $8.27 \pm 2.75$ & $8.07 \pm 0.96$ & $7.78 \pm 2.08$ & $16.55 \pm 2.09$ & $16.06 \pm 2.62$ \\
\hline Entorhinal & $8.10 \pm 0.98$ & $7.18 \pm 1.07$ & $7.53 \pm 0.92$ & $12.68 \pm 1.22$ & $12.55 \pm 0.75$ \\
\hline \multicolumn{6}{|l|}{ Forebrain } \\
\hline Hilus of the dentate gyrus & $7.29 \pm 0.65$ & $6.64 \pm 1.56$ & $6.77 \pm 1.03$ & $12.25 \pm 1.20$ & $12.12 \pm 1.11$ \\
\hline Medial amygdala & $8.79 \pm 0.32$ & $7.53 \pm 0.89^{*}$ & $8.11 \pm 0.87 *$ & $13.55 \pm 0.71$ & $13.09 \pm 1.28$ \\
\hline Basolateral amygdala & $8.81 \pm 0.25$ & $7.59 \pm 0.97 *$ & $8.30 \pm 1.07$ & $13.38 \pm 0.78$ & $12.65 \pm 0.95$ \\
\hline Caudate-putamen & $6.65 \pm 2.54$ & $6.47 \pm 1.07$ & $6.01 \pm 1.56$ & $12.84 \pm 1.89$ & $11.99 \pm 2.21$ \\
\hline Hypothalamus & $7.59 \pm 0.44$ & $6.72 \pm 0.89$ & $7.01 \pm 0.79$ & $14.24 \pm 1.13$ & $13.28 \pm 1.34$ \\
\hline \multicolumn{6}{|l|}{ Thalamus } \\
\hline Substantia nigra pars reticulata & $7.46 \pm 0.67$ & $7.83 \pm 2.57$ & $7.39 \pm 0.57$ & $13.32 \pm 1.78$ & $14.04 \pm 2.93$ \\
\hline Superior colliculus & $8.12 \pm 1.27$ & $7.55 \pm 0.84$ & $8.29 \pm 0.94$ & $13.69 \pm 1.39$ & $14.72 \pm 0.71$ \\
\hline Inferior colliculus & $12.69 \pm 1.43$ & $10.56 \pm 2.01$ & $14.78 \pm 2.48$ & $19.74 \pm 2.92$ & $21.91 \pm 3.52$ \\
\hline Pontine reticular formation & $11.19 \pm 1.03$ & $9.02 \pm 1.65$ & $10.97 \pm 1.75$ & $13.48 \pm 2.27$ & $16.22 \pm 2.17$ \\
\hline Cerebellar cortex & $9.08 \pm 0.79$ & $8.11 \pm 0.62$ & $9.60 \pm 1.59$ & $19.02 \pm 6.20$ & $17.77 \pm 1.60$ \\
\hline
\end{tabular}

Values, expressed as optical density $\times 100$, are means \pm SD of five to seven animals per group.

$* p<0.05$, statistically significant difference from corresponding control animals.

Table 2. Effect of lithium-pilocarpine SE on cytochrome oxidase activity in various cerebral regions of P21 rats

\begin{tabular}{|c|c|c|c|c|c|}
\hline & Control P21 rats & $4 \mathrm{~h}$ after SE & $24 \mathrm{~h}$ after SE & Control P35 rats & $14 \mathrm{~d}$ after SE \\
\hline \multicolumn{6}{|l|}{ Cerebral cortex } \\
\hline Frontal & $16.84 \pm 1.85$ & $13.56 \pm 2.43$ & $14.96 \pm 2.03$ & $16.85 \pm 1.38$ & $17.44 \pm 1.37$ \\
\hline Piriform & $16.84 \pm 0.97$ & $17.36 \pm 1.66$ & $16.57 \pm 0.81$ & $17.92 \pm 2.84$ & $18.08 \pm 1.87$ \\
\hline Sensorimotor & $16.73 \pm 1.50$ & $17.46 \pm 0.87$ & $17.78 \pm 1.61$ & $18.36 \pm 1.55$ & $18.91 \pm 1.04$ \\
\hline Entorhinal & $14.16 \pm 0.60$ & $13.70 \pm 1.32$ & $14.04 \pm 1.26$ & $14.88 \pm 1.69$ & $14.15 \pm 2.99$ \\
\hline \multicolumn{6}{|l|}{ Forebrain } \\
\hline Hilus of the dentate gyrus & $13.03 \pm 1.01$ & $12.37 \pm 1.13$ & $12.79 \pm 1.61$ & $14.72 \pm 1.91$ & $14.06 \pm 4.16$ \\
\hline Medial amygdala & $12.89 \pm 0.69$ & $11.34 \pm 1.11^{*}$ & $13.32 \pm 1.35$ & $14.89 \pm 1.79$ & $13.09 \pm 2.48$ \\
\hline Basolateral amygdala & $12.67 \pm 0.89$ & $12.34 \pm 0.82$ & $12.87 \pm 1.05$ & $14.53 \pm 1.48$ & $12.68 \pm 2.55$ \\
\hline Caudate-putamen & $13.17 \pm 0.70$ & $13.82 \pm 0.67$ & $13.31 \pm 0.96$ & $14.85 \pm 1.01$ & $15.20 \pm 1.06$ \\
\hline Hypothalamus & $14.10 \pm 0.97$ & $14.36 \pm 0.73$ & $14.35 \pm 1.20$ & $16.86 \pm 1.22$ & $14.81 \pm 2.98$ \\
\hline \multicolumn{6}{|l|}{ Thalamus } \\
\hline Substantia nigra pars reticulata & $14.86 \pm 2.04$ & $14.54 \pm 0.56$ & $14.87 \pm 1.89$ & $15.71 \pm 1.60$ & $15.49 \pm 1.13$ \\
\hline Superior colliculus & $12.91 \pm 1.29$ & $12.43 \pm 1.22$ & $12.78 \pm 2.66$ & $13.57 \pm 1.80$ & $14.53 \pm 2.47$ \\
\hline Inferior colliculus & $17.16 \pm 2.02$ & $15.38 \pm 2.47$ & $16.10 \pm 1.99$ & $16.76 \pm 2.23$ & $18.25 \pm 2.27$ \\
\hline Pontine reticular formation & $11.93 \pm 1.91$ & $11.60 \pm 2.10$ & $11.93 \pm 1.88$ & $11.84 \pm 0.74$ & $12.27 \pm 1.14$ \\
\hline Cerebellar cortex & $13.74 \pm 3.00$ & $15.95 \pm 2.45$ & $14.95 \pm 1.70$ & $17.65 \pm 0.74$ & $17.65 \pm 1.59$ \\
\hline
\end{tabular}

Values, expressed as optical density $\times 100$, are means \pm SD of five to seven animals per group.

$* p<0.05, * * p<0.01$, statistically significant differences from corresponding control animals.

adult (12-16), the developing, and the aging brain (16-20). Decreases in $\mathrm{CO}$ activity have been described after visual deprivation $(24,25)$, vibrissae removal, or deafferentation (26-28), whereas increases in CO activity were recorded during recovery from sensory deprivation (29). A close correlation between OD measurements of $\mathrm{CO}$ activity by diaminobenzidine histoenzymology, as performed in the present study and the activity of the enzyme measured spectrophotometrically has been established (13). The two latter measurements of enzyme activity are performed in vitro in optimal environmental conditions, mainly of $\mathrm{pH}$, substrate, and cofactors availability, and thus reflect the total enzyme activity present in the tissue but not the actual activity in in situ conditions. However, these measurements 
Table 3. Effect of lithium-pilocarpine SE on cytochrome oxidase activity in various cerebral regions of adult rats

\begin{tabular}{|c|c|c|c|c|}
\hline & Control adult rats & $4 \mathrm{~h}$ after SE & $24 \mathrm{~h}$ after SE & $14 \mathrm{~d}$ after SE \\
\hline \multicolumn{5}{|l|}{ Cerebral cortex } \\
\hline Frontal & $15.28 \pm 1.11$ & $14.32 \pm 0.37$ & $14.50 \pm 2.52$ & $15.28 \pm 2.18$ \\
\hline Piriform & $17.14 \pm 1.05$ & $17.38 \pm 0.64$ & $14.20 \pm 2.23$ & $17.92 \pm 5.19$ \\
\hline Sensorimotor & $14.64 \pm 1.09$ & $13.94 \pm 0.69$ & $14.24 \pm 2.46$ & $15.19 \pm 2.20$ \\
\hline Entorhinal & $14.29 \pm 0.98$ & $13.20 \pm 0.87$ & $8.28 \pm 1.63^{* *}$ & $6.73 \pm 1.11^{* *}$ \\
\hline \multicolumn{5}{|l|}{ Forebrain } \\
\hline Hilus of the dentate gyrus & $14.85 \pm 1.02$ & $13.63 \pm 1.26$ & $13.33 \pm 3.48$ & $15.95 \pm 0.92$ \\
\hline Medial amygdala & $16.05 \pm 1.22$ & $13.94 \pm 0.50^{* *}$ & $12.78 \pm 3.20^{*}$ & $15.21 \pm 0.97$ \\
\hline Basolateral amygdala & $14.35 \pm 1.03$ & $13.82 \pm 1.15$ & $12.04 \pm 3.24$ & $14.79 \pm 1.96$ \\
\hline Caudate-putamen & $12.35 \pm 1.33$ & $12.08 \pm 1.14$ & $13.25 \pm 1.17$ & $14.31 \pm 1.60^{*}$ \\
\hline Hypothalamus & $16.85 \pm 2.07$ & $16.73 \pm 1.10$ & $16.01 \pm 3.87$ & $18.27 \pm 2.36$ \\
\hline \multicolumn{5}{|l|}{ Thalamus } \\
\hline Substantia nigra pars reticulata & $15.80 \pm 0.86$ & $13.80 \pm 0.89^{*}$ & $12.50 \pm 2.61^{* *}$ & $15.71 \pm 1.57$ \\
\hline Superior colliculus & $13.84 \pm 0.94$ & $14.19 \pm 1.58$ & $13.80 \pm 2.52$ & $16.14 \pm 1.15^{*}$ \\
\hline Inferior colliculus & $15.29 \pm 2.22$ & $15.94 \pm 1.33$ & $17.24 \pm 3.20$ & $19.31 \pm 1.94 *$ \\
\hline Pontine reticular formation & $9.10 \pm 0.58$ & $9.52 \pm 1.43$ & $9.97 \pm 2.33$ & $11.65 \pm 2.07^{* *}$ \\
\hline Cerebellar cortex & $15.86 \pm 1.36$ & $16.03 \pm 3.12$ & $15.14 \pm 3.57$ & $18.03 \pm 2.22$ \\
\hline
\end{tabular}

Values, expressed as optical density $\times 100$, are means \pm SD of five to seven animals per group.

$* p<0.05, * * p<0.01$, statistically significant differences from control animals.

Table 4. Effect of lithium-pilocarpine SE on lactate dehydrogenase activity in various cerebral regions of adult rats

\begin{tabular}{|c|c|c|c|c|}
\hline & Control adult rats & $4 \mathrm{~h}$ after SE & $24 \mathrm{~h}$ after SE & $14 \mathrm{~d}$ after SE \\
\hline \multicolumn{5}{|l|}{ Cerebral cortex } \\
\hline Frontal & $6.79 \pm 1.15$ & $6.06 \pm 1.71$ & $5.44 \pm 1.52$ & $5.64 \pm 1.49$ \\
\hline Piriform & $7.02 \pm 0.14$ & $6.88 \pm 2.15$ & $8.17 \pm 0.54^{*}$ & $5.93 \pm 1.60$ \\
\hline Sensorimotor & $6.97 \pm 0.95$ & $5.31 \pm 1.57$ & $4.92 \pm 1.93$ & $5.19 \pm 1.39^{*}$ \\
\hline Entorhinal & $8.63 \pm 0.69$ & $7.98 \pm 1.14$ & $6.05 \pm 2.57$ & $3.29 \pm 1.19^{* *}$ \\
\hline \multicolumn{5}{|l|}{ Forebrain } \\
\hline Hilus of the dentate gyrus & $7.23 \pm 0.57$ & $6.25 \pm 1.21$ & $7.56 \pm 1.00$ & $7.38 \pm 1.29$ \\
\hline Medial amygdala & $7.11 \pm 0.95$ & $6.20 \pm 0.81$ & $7.31 \pm 1.38$ & $6.75 \pm 1.92$ \\
\hline Basolateral amygdala & $7.73 \pm 0.65$ & $7.61 \pm 1.26$ & $9.69 \pm 0.88$ & $6.86 \pm 1.36$ \\
\hline Caudate-putamen & $7.64 \pm 1.77$ & $6.05 \pm 1.51$ & $6.97 \pm 1.08$ & $7.01 \pm 0.84$ \\
\hline Hypothalamus & $5.43 \pm 0.39$ & $5.59 \pm 0.66$ & $6.62 \pm 0.58$ & $5.11 \pm 1.37$ \\
\hline \multicolumn{5}{|l|}{ Thalamus } \\
\hline Substantia nigra pars reticulata & $6.83 \pm 2.47$ & $5.09 \pm 0.98$ & $6.79 \pm 1.29$ & $6.30 \pm 1.12$ \\
\hline Superior colliculus & $5.33 \pm 0.49$ & $5.28 \pm 1.21$ & $6.37 \pm 1.17^{*}$ & $5.51 \pm 1.09$ \\
\hline Inferior colliculus & $4.62 \pm 0.45$ & $5.26 \pm 1.47$ & $5.20 \pm 0.87$ & $5.02 \pm 1.26$ \\
\hline Pontine reticular formation & $5.33 \pm 0.98$ & $6.00 \pm 1.89$ & $5.64 \pm 0.91$ & $5.91 \pm 1.33$ \\
\hline Cerebellar cortex & $11.07 \pm 4.29$ & $7.29 \pm 1.59$ & $7.26 \pm 2.53$ & $7.09 \pm 2.33$ \\
\hline
\end{tabular}

Values, expressed as optical density $\times 100$, are means \pm SD of five to seven animals per group.

$* p<0.05 ; * * p<0.01$, statistically significant differences from control animals.

of enzyme activity have been shown to closely reflect the long-term functional use of the pathways of aerobic glucose metabolism. A direct positive correlation has been established between capillary density and $\mathrm{CO}$ activity or cerebral glucose utilization in the rat $(12,30)$. Conversely, the relationship between LDH activity and capillary density is a negative one, raising the possibility that brain regions with a high glycolytic capacity may require fewer capillaries (12). The regional heterogeneity of both LDH and CO activities as shown in the literature and the present study are in favor of the hypothesis that the different brain regions are composed of a mixture of oxidative and glycolytic zones reflecting cellular heterogeneity, as well as a heterogeneous pattern of innervation (12). 
The activities of CO and LDH that reflect the anaerobic and oxidative parts of glucose degradation are also often compared with the $\left[{ }^{14} \mathrm{C}\right] 2 \mathrm{DG}$ technique. The $\left[{ }^{14} \mathrm{C}\right] 2 \mathrm{DG}$ method measures the uptake and phosphorylation of $\left[{ }^{14} \mathrm{C}\right] 2 \mathrm{DG}$ to $\left[{ }^{14} \mathrm{C}\right] 2 \mathrm{DG}-6 \mathrm{P}$ over a given period of time, usually $45 \mathrm{~min}$, and represents the sum of the glycolytic and oxidative pathways $(31,32)$. In contrast, the levels of the enzymes of glucose metabolism, i.e. $\mathrm{LDH}$ and $\mathrm{CO}$, are regulated according to glycolytic and oxidative metabolic needs, respectively, during the hours or days before tissue is obtained (16). Thus, the two methods reveal cerebral activity through different temporal and metabolic windows.

Maturation of $\mathbf{L D H}$ and $\mathbf{C O}$. The pattern of maturation of both LDH and CO measured by histoenzymology is in good accordance with previous studies using both histoenzymology and enzymatic approaches. At birth, the activity of LDH is only 1.7- to 3-fold lower than in the adult brain and reaches a maximal value between P10 (as in the present study) and P17 according to the isoenzyme studied (17,33-36). The decrease of LDH activity that we recorded between P10 and P21 in the present study parallels the maturation of the $\mathrm{H} 4$ isoenzyme that predominates in neurons (37) and reflects also the transition between the anaerobic and the aerobic metabolism of glucose $(38,39)$. The lack of change in the activity of LDH after P21 is also in accordance with the maturation-related change in the isoenzymatic composition of the enzyme, which has reached its adult level by that age (38).

Conversely to the activity of $\mathrm{LDH}$, the regional cerebral activity of $\mathrm{CO}$ is low at birth and increases by 5 - to 8 -fold until maturity with the fastest increase occurring between P10 and P30 (17,40-42). This reflects the shift from the anaerobic to the aerobic metabolism and the increase in the numerical density of mitochondria, of their relative volume, and number of cristae (43). The maturation of $\mathrm{CO}$ that takes place at least until P21 and in some structures until P35 parallels that of the other enzymes of oxidative glucose metabolism such as citrate synthase, fumarase, and $\mathrm{NAD}^{+}$-isocitrate dehydrogenase (33) and also the general maturation pattern of the electron transport chain and oxidative phosphorylation in the rat brain (44). Finally, the activity of $\mathrm{CO}$ is lowest in white matter compared with gray matter areas, which is in line with the relative poverty of mitochondria in the former structures.

Changes in CO and LDH induced by Li-Pilo SE. The immediate consequences of Li-Pilo SE on total CO activity were limited. At $4 \mathrm{~h}$ after SE, decreases in activity occurred in medial amygdala at the three ages studied, basolateral amygdala and ventromedian thalamus at P10. In adult rats, decreases in $\mathrm{CO}$ activity were also found in the hippocampal CA3 pyramidal cell layer, the whole thalamus, and substantia nigra pars reticulata. By $24 \mathrm{~h}$ after SE, decreases in CO activity persisted in medial amygdala at $\mathrm{P} 10$, and were present in hippocampal CA3 pyramidal cell layer in P21 and adult rats, and entorhinal cortex, medial amygdala, and substantia nigra pars reticulata in adult rats. At the two older ages, decreases in $\mathrm{CO}$ activity are located in areas in which neuronal damage was recorded $(5,7,9,11)$, but, interestingly, not all areas in which neuronal damage was observed underwent decreases in $\mathrm{CO}$ activity. The lesser extent of change in enzyme activity in P21 compared with adult rats reflects the more limited damage occurring at the former age $(5,7,11)$. Medial amygdala is indeed one of the few structures undergoing neuronal damage after Li-Pilo SE at P21. However, the hilus of the dentate gyrus, lateral thalamus, and entorhinal cortex also undergo cell damage in P21 rats (7), whereas CO activity is not affected in these structures. Conversely, hippocampal CA3 area in which $\mathrm{CO}$ activity is decreased at $24 \mathrm{~h}$ after SE in P21 rats does not undergo neuronal loss at that age (7). In adult rats, all the regions in which $\mathrm{CO}$ activity is decreased at 4 and $24 \mathrm{~h}$ after SE undergo cell damage (7). But, as at P21, there are areas in which $\mathrm{CO}$ activity is not affected by SE whereas neuronal loss is extended, like the piriform cortex, hippocampal CA1 layer, and the hilus of the dentate gyrus $(5,7,11)$. The lack of change in the total capacity of these areas closely corresponds to the maintenance of a relatively high, sometimes normal metabolic activity recorded in these areas by means of the 2DG technique. These areas, and mainly the piriform cortex and hilus of the dentate gyrus, appear to be metabolically hyperactive compared with the number of surviving neurons $(5,7)$ and have also been shown to be key areas for the initiation of the epileptic process for the former one $(45,46)$ and for the maintenance of the disease for the latter one $(5,7)$. In the P10 rat, there is only a transient decrease in $\mathrm{CO}$ activity in the ventrolateral thalamus and medial and basolateral amygdala recorded at $4 \mathrm{~h}$ after SE onset, whereas decreased $\mathrm{CO}$ activity persists in medial amygdala up to $24 \mathrm{~h}$ after SE onset at that early age. At P10, Li-Pilo SE does not induce any overt damage $(5,7,9,11)$, although the decrease in $\mathrm{CO}$ activity in the first $24 \mathrm{~h}$ after SE in thalamus and amygdala of P10 rats may indicate a marked sensitivity of these brain areas to cellular disturbances induced by SE. Indeed, thalamus is the only structure in which FluoroJade B positive neurons can be found in $\mathrm{P} 12$ rats subjected to Li-Pilo SE, indicating the early vulnerability of this structure (47). The lack of long-term consequences on CO activity measured $14 \mathrm{~d}$ after SE induced in P10 rats is in accordance with our previous observations showing that SE leads to immediate cell suffering in P10 rats but neurons are able to recover without undergoing neuronal death like at older ages (48).

During the latent phase, at $14 \mathrm{~d}$ after SE, the only decrease in $\mathrm{CO}$ activity that remains can be found in the entorhinal cortex of rats that were subjected to Li-Pilo SE as adults. The latter structure is damaged after SE and characterized at that stage by a low metabolic activity $(5,7)$ which is in line with the decrease of the total enzymatic capacity of the oxidative pathway of glucose degradation. All the other structures that had decreased CO activity in the $24 \mathrm{~h}$ after SE at the three ages have recovered their level of oxidative enzymatic activity. The full recovery of CO activity in damaged areas is in line with the normometabolic activity that we recorded previously at the same time in damaged areas in the face of extended neuronal loss, reflecting a relative hypermetabolic activity $(5,7,11)$. In addition, at $14 \mathrm{~d}$ after $\mathrm{SE}$ in adult rats, some regions exhibit increases of $\mathrm{CO}$ activity over control levels. These regions are the caudate-putamen, superior and inferior colliculus, reticular formation, and cerebellar cortex. In most of these regions, LCMRglcs were also increased at $14 \mathrm{~d}$ after SE $(5,7)$. Almost 
all the structures with increased $\mathrm{CO}$ activity in adult rats belong to the circuitry of basal ganglia that are involved in the control of motor functions, cognitive and motivational processes $(49,50)$, and the control of epileptic seizures (51-53). The activation of the brainstem circuit of remote control of seizures is able to block seizures induced by pilocarpine $(4,54)$, amygdala-kindled seizures, and the kindling process itself (55). The metabolic increase recorded in the superior colliculus, reticular formation, and caudate-putamen mainly during the latent phase of adult rats could reflect the activation of the remote system of control of the epilepsies relating to the development of a new circuit that underlies the occurrence of spontaneous seizures. Metabolic levels are also increased in cerebellar cortex and nuclei at $14 \mathrm{~d}$ after SE in adult rats. These data correlate with the observation that the cerebellum exerts a tonic effect over the circuit involved in the kindling process (56) and seizures induced by bicuculline (57). Cerebellar stimulation has indeed been used decades ago to control epilepsy in humans (58).

We studied also the activity of CO in the different cell layers of the hippocampus of adult rats (data not shown). The only main change was a decrease in $\mathrm{CO}$ activity in the inner and outer molecular layers of the dentate gyrus at $14 \mathrm{~d}$ after SE. These layers receive the innervation of afferent fibers from the entorhinal cortex (59), which is severely damaged $(5,7,45)$ and whose CO activity is also decreased at that time. Thus, as reported previously, the activity of neuronal $\mathrm{CO}$ is directly related to functional afferences (16) and the decrease of $\mathrm{CO}$ activity at the level of the inner molecular layer of the dentate gyrus most likely reflects the partial deafferentation of the entorhinal cortex consecutive to the lesional process. Similar decreases in $\mathrm{CO}$ activity have been reported after visual deprivation $(24,25)$, or vibrissae removal or deafferentation (26-28).

As expected, LDH activity was less affected in adult rats by Li-Pilo SE than the oxidative pathway of glucose degradation reflected by $\mathrm{CO}$ activity. Increases in $\mathrm{LDH}$ activity were recorded at $24 \mathrm{~h}$ after $\mathrm{SE}$ in piriform cortex, mediodorsal thalamus, and superior colliculus of rats subjected to SE as adults. These increases in LDH activity occur in both regions undergoing damage (piriform cortex and mediodorsal thalamus) or not (superior colliculus). These transient increases may reflect a compensatory mechanism in damaged areas. Indeed, in the piriform cortex and thalamus of adult rats subjected to Li-Pilo SE, neuronal damage is fast and almost totally developed by $24 \mathrm{~h}$ after SE (45). This local increase in LDH activity may reflect the activation of anaerobic glycolysis taking place in astrocytes. Indeed this cell population has been shown to metabolize glucose mainly via anaerobic glycolysis (60) and gliosis is occurring in damaged areas of adult rats subjected to Li-Pilo SE (45). In the superior colliculus that is not damaged by $\mathrm{SE}$, the increase of $\mathrm{LDH}$ activity may reflect, as for $\mathrm{CO}$ activity, the activation of the circuit of seizure control to which this structure belongs (51-53). Indeed, Li-Pilo SE is characterized by long-lasting SE (about $8 \mathrm{~h}$ ) followed by recurrent seizures over the first $48 \mathrm{~h}$ after SE onset $(7,9,11)$. Thus, the circuit of seizure control may be activated already during that early phase of recurrent seizure activity. By $14 \mathrm{~d}$ after SE, LDH activity is only decreased in sensorimotor and entorhinal cortices. These two cortices undergo neuronal damage but, com- pared with other regions like the piriform cortex, amygdala, or hippocampus, neuronal death is limited in extension in these two regions. Thus, these cortical decreases in LDH activity may reflect either specific local changes or the more limited astrocytic reaction inasmuch as damage is less extended. In the more extensively damaged regions, the active gliosis may compensate for neuronal loss and allow the enzymatic activity of the whole region to remain stable. This is in line with our prior observations in this model showing that there is no direct correlation between the large extent of neuronal loss and the metabolic level that remains in the normal range in regions like the piriform cortex, thalamus, and hilus of the dentate gyrus $(5,7,11)$. The present data would therefore be in favor of a preservation of metabolic activity at least partly via the anaerobic pathway of glucose degradation.

In conclusion, the changes in the anaerobic and oxidative pathways of glucose utilization induced by Li-Pilo SE are age dependent and most marked in adult animals. They reflect, in part, the lesional process and, in part, the high activity of the circuit activated to control seizures. The total enzymatic capacity of glucose oxidation in brain tissue appears to be better preserved than the actual levels of glucose utilization.

\section{REFERENCES}

1. Camfield P, Camfield C, Gordon K, Dooley J 1994 What types of epilepsy are preceded by febrile seizures? A population-based study of children. Dev Med Child Neurol 36:887-892

2. French JA, Williamson PD, Thadani VM, Darcey TM, Mattson RH, Spencer SS, Spencer DD 1993 Characteristics of medial temporal lobe epilepsy: I. Results of history and physical examination. Ann Neurol 34:774-780

3. Mathern GW, Kuhlman PA, Mendoza D, Pretorius JK 1997 Human fascia dentate anatomy and hippocampal neuron densities differ depending on the epileptic syndrome and age at first seizures. J Neuropathol Exp Neurol 56:199-212

4. Turski L, Ikonomidou C, Turski WA, Bortolotto ZA, Cavalheiro EA 1989 Review: Cholinergic mechanisms and epileptogenesis. The seizures induced by pilocarpine: a novel experimental model of intractable epilepsy. Synapse 3:154-171

5. Dubé C, Marescaux C, Nehlig A 2000 A metabolic and neuropathological approach to the understanding of plastic changes occurring in the immature and adult rat brain during lithium-pilocarpine induced epileptogenesis. Epilepsia 41:S36-S43

6. Cavalheiro EA, Silva DF, Turski WA, Calderazzo-Filho LS, Bortolotto ZA, Turski L 1987 The susceptibility of rats to pilocarpine-induced seizures is age-dependent. Dev Brain Res 465:43-58

7. Dubé C, Boyet S, Marescaux C, Nehlig A 2001 Relationship between neuronal loss and interictal metabolism during the chronic phase of the lithium-pilocarpine model of epilepsy in the immature and adult rat. Exp Neurol 167:227-241

8. Nehlig A, Pereira de Vasconcelos AP, Boyet S 1988 Quantitative autoradiographic measurement of local cerebral glucose utilization in freely moving rats during postnatal development. J Neurosci 8:2321-2333

9. Fernandes MJ, Dubé C, Boyet S, Marescaux C, Nehlig A 1999 Correlation between hypermetabolism and neuronal damage during status epilepticus induced by lithium and pilocarpine in immature and adult rats. J Cereb Blood Flow Metab 19:195-209

10. Vannucci SJ 1994 Developmental expression of GLUT1 and GLUT3 glucose transporters in rat brain. J Neurochem 62:240-246

11. Dubé C, Boyet S, Marescaux C, Nehlig A 2000 Progressive metabolic changes underlying the chronic reorganization of brain circuits during the silent phase of the lithium-pilocarpine model of epilepsy in the immature and adult rat. Exp Neurol 162:146-157

12. Borowsky IW, Collins RC 1989 Metabolic anatomy of brain: a comparison of regional capillary density, glucose metabolism, and enzyme activities. J Comp Neurol 288:401-413

13. Darriet D, Der T, Collins RC 1986 Distribution of cytochrome oxidase in rat brain: studies with diaminobenzidine histochemistry in vitro and $\left[{ }^{14} \mathrm{C}\right]$ cyanide tissue labeling in vivo. J Cereb Blood Flow Metab 6:8-14

14. Dufour F, Koning E, Nehlig A 2003 Basal levels of metabolic activity are elevated in Genetic Absence Epilepsy Rats from Strasbourg (GAERS): measurement of regional activity of cytochrome oxidase and lactate dehydrogenase by histochemistry. Exp Neurol 182:346-352

15. Hevner RF, Liu S, Wong-Riley MT 1995 A metabolic map of cytochrome oxidase in the rat brain: histochemical, densitometric and biochemical studies. Neuroscience 65:313-342

16. Wong-Riley MT 1989 Cytochrome oxidase: an endogenous metabolic marker for neuronal activity. Trends Neurosci 12:94-101 
17. Bilger A, Nehlig A 1991 Quantitative histochemical changes in enzymes involved in energy metabolism in the rat brain during postnatal development. I. Cytochrome oxidase and lactate dehydrogenase. Int J Dev Neurosci 9:545-553

18. Curti D, Giangare MC, Redolfi ME, Fugaccia I, Benzi G 1990 Age-related modifications of cytochrome $c$ oxidase activity in discrete brain regions. Mech Ageing Dev 55:171-180

19. Gonzalez-Pardo H, Novelli A, Menendez-Patterson A, Arias JL 1996 The development of oxidative metabolism in diencephalic structures of the rat: a quantitative study. Brain Res Bull 41:31-38

20. Hovda DA, Villablanca JR 1998 Cerebral metabolism following neonatal or adul hemidecortication in cats: effect on oxidative capacity using cytochrome oxidase histochemistry. Brain Res Dev Brain Res 110:39-50

21. Tuor UI, Kurpita G, Simone C 1994 Correlation of local changes in cerebral blood flow, capillary density, and cytochrome oxidase during development. J Comp Neurol 342:439-448

22. Jacobsen NO 1969 The histochemical localization of lactic dehydrogenase isoenzymes in the rat nephron by means of an improved polyvinyl alcohol method. Histochemie 20:250-265

23. Paxinos G, Watson C 1986 The Rat Brain in Stereotaxic Coordinates. Academic Press, New York

24. Rosa MG, Gattass R, Soares JG 1991 A quantitative analysis of cytochrome oxidaserich patches in the primary visual cortex of Cebus monkeys: topographic distribution and effects of late monocular enucleation. Exp Brain Res 84:195-209

25. Wong-Riley M, Carroll EW 1984 Effect of impulse blockage on cytochrome oxidase activity in monkey visual system. Nature 307:262-264

26. Borowsky IW, Collins RC 1989 Histochemical changes in enzymes of energy metabolism in the dentate gyrus accompany deafferentation and synaptic reorganization. Neuroscience 33:253-262

27. Villablanca JR, Schmanke TD, Hovda DA 1999 Effects of a restricted unilatera neocortical lesion upon cerebral glucose and oxidative metabolisms in fetal and neonatal cats. Brain Res Dev Brain Res 117:1-13

28. Wong-Riley MT, Welt C 1980 Histochemical changes in cytochrome oxidase of cortical barrels after vibrissal removal in neonatal and adult mice. Proc Natl Acad Sci U S A 77:2333-2337

29. Dietrich WD, Durnham D, Lowry OH, Woolsey TA 1982 "Increased" sensory stimulation leads to changes in energy-related enzymes in the brain. J Neurosci 2:1608-1613

30. Klein B, Kuschinsky W, Schröck H, Vetterlein F 1986 Interdependency of loca capillary density, blood flow, and metabolism in rat brains. Am J Physiol 251:H1333H1340

31. Sokoloff L 1982 The radioactive deoxyglucose method. Theory, procedure, and applications for the measurement of local glucose utilization in the central nervous system. In: Agranoff BW, Aprison MH (eds) Advances in Neurochemistry, Vol IV. Plenum, New York, pp 1-82

32. Sokoloff L, Reivich M, Kennedy C, Des Rosiers MH, Patlak CS, Pettigrew KD, Sakurada O, Shinohara M 1977 The $\left[{ }^{14} \mathrm{C}\right] 2$-deoxyglucose method for the measurement of local cerebral glucose utilization: theory, procedure, and normal values in the conscious and anesthetized albino rat. J Neurochem 28:897-916

33. Booth RF, Patel TB, Clark JB 1980 The development of enzymes of energy metabolism in the brain of a precocial (guinea pig) and non precocial (rat) species. J Neurochem 34:17-25

34. Leong SF, Clark JB 1984 Regional enzyme development in rat brain. Enzymes associated with glucose utilization. Biochem J 218:131-138

35. Leong SF, Clark JB 1984 Regional enzyme development in rat brain. Enzymes of energy metabolism. Biochem J 218:139-145

36. Takagaki G 1974 Developmental changes in glycolysis in rat cerebral cortex. J Neurochem 23:479-487

37. Bonavita V 1964 Molecular evolution of lactate dehydrogenase in the developing nervous tissue. Progr Brain Res 4:254-272
38. Bonavita V, Ponte F, Amore G 1962 Lactate dehydrogenase isozymes in the developing rat brain. Nature 196:576-577

39. Ford DH 1973 Selected maturational changes observed in the postnatal rat brain Progr Brain Res 40:1-12

40. Hamburg M, Flexner LB 1957 Biochemical and physiological differentiation during morphogenesis. XXI. Effect of hypothyroidism and hormone therapy on enzyme activities of the developing cerebral cortex of the rat. J Neurochem 1:279-288

41. Klee CB, Sokoloff L 1967 Changes in D(-)- $\beta$-hydroxybutyrate dehydrogenase activity during brain maturation of the rat. J Biol Chem 242:3880-3883

42. Murakami DM, Fuller CA 1988 The postnatal development of oxidative metabolism in the suprachiasmatic nucleus of the rat. Neuroscience 24:977-986

43. Pysh JJ 1970 Mitochondrial changes in rat inferior colliculus during postnatal development: an electron microscopic study. Brain Res 18:325-342

44. Almeida A, Brooks KJ, Sammut I, Keelan J, Davey GP, Clark JB, Bates TE 1995 Postnatal development of the complexes of the electron transport chain in synaptic mitochondria from rat brain. Dev Neurosci 17:212-218

45. Roch C, Leroy C, Nehlig A, Namer IJ 2002 Magnetic resonance imaging in the study of the lithium-pilocarpine model of temporal lobe epilepsy in adult rats. Epilepsia 43:325-335

46. Roch C, Leroy C, Nehlig A, Namer IJ 2002 Predictive value of cortical injury for development of temporal lobe epilepsy in 21-day-old rats: an MRI approach using the lithium-pilocarpine model. Epilepsia 43:1129-1136

47. Kubova H, Druga R, Lukasiuk K, Suchomelova L, Haugvicova R, Jirmanova I, Pitkanen A 2001 Status epilepticus causes necrotic damage in the mediodorsa nucleus of the thalamus in immature rats. J Neurosci 21:3593-3529

48. Pineau N, Charriaut-Marlangue C, Motte J, Nehlig A 1999 Pentylenetetrazol seizures induce cell suffering but not death in the immature rat brain. Brain Res Dev Brain Res 112:139-144

49. Bevan MD, Smith AD, Bolam JP 1996 The substantia nigra as a site of synaptic integration of functionally diverse information arising from the ventral pallidum and the globus pallidus in the rat. Neuroscience 75:5-12

50. Calabresi P, De Murtas M, Bernardi G 1997 The neostriatum beyond the motor function: experimental and clinical evidence. Neuroscience 78:39-60

51. Depaulis A, Vergnes M, Marescaux C 1994 Endogenous control of epilepsy: the nigral inhibitory system. Progr Neurobiol 42:33-52

52. Deransart C, Vercueil L, Marescaux C, Depaulis A 1998 The role of basal ganglia in the control of generalized absence seizures. Epilepsy Res 32:213-223

53. Garant DS, Gale K 1987 Substantia nigra-mediated anticonvulsant actions: role of nigral output pathways. Exp Neurol 97:143-159

54. Cavalheiro EA, Turski L 1986 Intrastriatal $N$-methyl-D-aspartate prevents amygdala kindled seizures in rats. Brain Res 377:173-176

55. Löscher W, Czuczwar SJ, Jäkel R, Schwarz M 1987 Effects of microinjections of gamma-vinyl GABA or isoniazid into substantia nigra on the development of amygdala kindling in rats. Exp Neurol 95:622-638

56. Paz C, Gutiérrez-Baeza F, Bazán-Perkins B 1991 Transection of the superior cerebellar peduncle interferes with the onset and duration of generalized seizures induced by amygdaloid kindling. Brain Res 558:90-92

57. Miller JW, Gray BC, Turner GM 1993 Role of the fastigial nucleus in generalized seizures as demonstrated by GABA agonist microinjections. Epilepsia 34:973-978

58. Cooper IS, Riklan M, Amin I, Cullinan T 1978 A long-term follow-up study of cerebellar stimulation for the control of epilepsy. In: Cooper IS (ed) Cerebellar Stimulation in Man. Raven Press, New York, pp 19-38

59. Turner DA, Buhl EH, Hailer NP, Nitsch R 1998 Morphological features of the entorhinal-hippocampal connection. Progr Neurobiol 55:537-562

60. Magistretti PJ, Pellerin L 1996 Cellular bases of brain energy metabolism and their relevance to functional brain imaging: evidence for a prominent role of astrocytes. Cerebral Cortex 6:50-61 